Our patient had no evidence of any underlying bony abnormality predisposing to fracture and the radiological appearances of the healing fracture were also entirely normal. Pregnancy can be associated with a generalised decreased bone density usually causing back pain and possibly vertebral compression fractures but this is uncommon. ${ }^{3}$ The "transient osteoporosis of the hip in pregnancy" is also rare but can lead to pathological femoral neck fractures but this is usually late in the third trimester. ${ }^{4}$ Stress fractures are also found but usually involve the pubis in late. pregnancy, often related to childbirth. ${ }^{5}$ Our patient had no evidence to suggest any such predisposing factors.

The diagnosis of a femoral shaft fracture with ultrasound in our patient was fortuitous for several reasons. Firstly a femoral shaft fracture in a young adult usually requires significant trauma and the index of suspicion for such an injury in our patient was low. Secondly the patient was pregnant so ultrasound was used to establish the diagnosis and subsequent $x$ ray irradiation of the fetus was minimised. Thirdly, the patient could not localise an area of focal tenderness and the pelvic radiograph initially requested to exclude a hip injury would have missed the femoral shaft fracture, unnecessarily irradiated the fetus, and incorrectly reassured the casualty staff.

1 DaCruz DJ, Taylor RH, Savage B, et al. Ultrasound assessment of the suspected scaphoid fracture. Arch Emerg Med 1988;5:97-100.

2 Gleeson AP, Stuart MJ, Wilson B, et al. Ultrasound assessment and conservative management of inversion injuries of the ankle in children. $\mathcal{F}$ Bone foint Surg $\mathrm{Br} 1996 ; 78: 484-7$.

3 Dunne F, Walters, Marshall T, et al. Pregnancy associated osteoporosis. Clin Endocrinol (Oxf) 1993;39:487-90.

4 Junk S, Ostrwski M, Kokosczczynski L. Transient osteoporosis of the hip in pregnancy complicated by femoral neck fracture. Acta Orthop Scand 1996;67:69-70.

5 Maron JJM. Stress fractures in pregnancy. Am $f$ Obstet Gynecol 1988;158:1274-7.

\title{
Plain abdominal radiography in the diagnosis of the "body packer"
}

\author{
A Krishnan, R Brown
}

Plain abdominal radiography remains an important tool in the management of cases of suspected drug smuggling by internal body concealment ("body packing").

A 29 year old man presented to the accident and emergency department after allegedly taking an oral overdose of the drug ecstasy, while he was in police custody. He also stated that he was transporting two sealed containers in his rectum, each containing approximately 70 ecstasy tablets.

A plain abdominal radiograph demonstrated two well circumscribed foreign bodies lying within the pelvis (fig 1). Other investigations were normal. The patient was subsequently managed conservatively after the natural expulsion of the two foreign bodies.

Where the internal concealment of drugs is suspected, their existence and location must be accurately determined. Plain abdominal radiography is an important and effective method of diagnosis. The transporting materials are usually sealed condoms or similar materials. Air can leak into these packs and

King's College School of Medicine and Dentistry, King's College Hospital, Denmark Hill, London SE5 9RS

A Krishnan

R Brown

Correspondence to: Mr Krishnan, Medical Student. create a characteristic gas halo or ring shadow, easily detectable by radiography. ${ }^{1}$ Radiography may detect over $80 \%$ of such concealed packages, ${ }^{2}$ but the use of wrapped or aluminium foil packs are more likely to lead to a false positive result. ${ }^{3}$ The dense nature of the container used for concealment in this case (the "Kinder egg") made it easily detectable. Although ultrasound may be a valuable

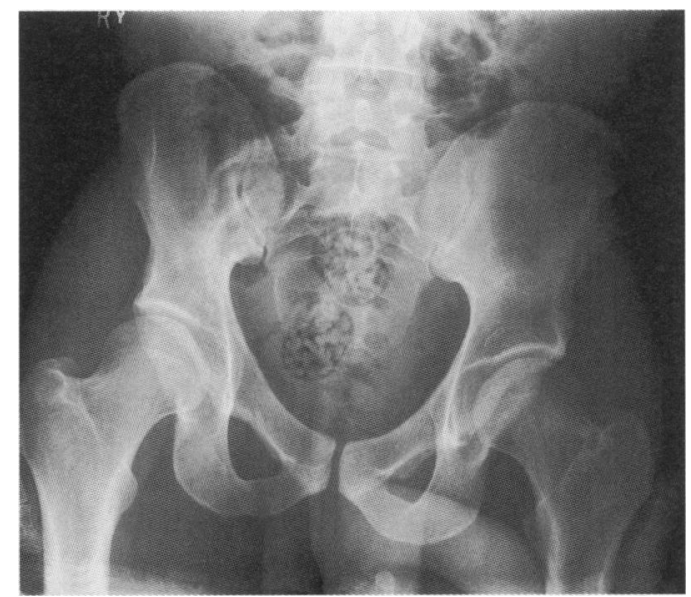

Figure 1 Radiograph showing two foreign bodies.

diagnostic tool in these cases, radiography may be superior in the differentiation of ingested packages. ${ }^{4}$ Additional investigations, such as urinary drug screening or bowel contrast studies, should be used where the diagnosis is equivocal. ${ }^{3}$

1 Lancashire MJR, Legg PK, Lowe M, et al. Surgical aspects of international drug smuggling. BMF 1998;296:1035-7.

2 Karhunen PJ, Suoranta H, Pentilla A, et al. (1991) Pitfalls in 1991;36:397-402.

3 Gherardi R, Marc B, Alberti X, et al. A cocaine body packer with normal abdominal plain radiograms. Value of drug detection in urine and contrast study
Forensic Med Pathol 1990;11:154-7.

4 Hierholzer J, Cordes M, Tantow H, et al. Drug smuggling by ingested cocaine-filled packages: conventional $\mathrm{x}$-ray and ultrasound. Abdom Imaging 1995;20:333-8. 